\title{
Moral Attributes In A Dictator Game
}

\author{
Brian T. Kench, (E-mail: bkench@ut.edu), University of Tampa \\ Robert L. Beekman, (E-mail: rbeekman@ut.edu), University of Tampa \\ Wanda V. Chaves, (E-mail: wchaves@ut.edu), University of Tampa \\ Neil B. Niman, (E-mail: neil@ orbit.unh.edu), University of New Hampshire
}

\begin{abstract}
This paper investigates whether or not the moral factors captured in an emotional intelligence assessment matter in the economic decisions made by subjects in a dictator game. We find a statistically significant relationship between the amount of the dictator's contribution and a few of the factors of the Intrapersonal Dimension of the EQ-i. We also find a significant relationship between dictator contributions and an adjusted EQ-i score, measures of independence, know-myown and empathy. Our results may be relevant to researchers interested in understanding the preference set of economic decision-makers. Moreover, for those interested in refining experimental design protocols, we show the EQ-i to be a useful resource to control for a few of the moral attributes Levitt et al. (2006) suggest are so very important in understanding laboratory and field experiments.
\end{abstract}

Key Words: Emotional Intelligence, Dictator Game, Behavioral Economics

\section{INTRODUCTION}

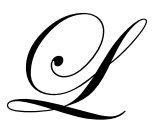

evitt et al. (2006, pp. 2-3) argue that human decisions are influenced not just by simple monetary calculations, but also by the nature and extent to which one's actions are scrutinized by others, the particular context and process by which a decision is embedded, and self-selection of the individuals making the decisions. Levitt et al. (2006) offer a model of utility maximization that depends on wealth and an individual's desire to "do the right thing" or make the "moral" choice. ${ }^{1}$ The weight an individual places on such moral desires is likely to increase when a subject is being watched, when the decision process is emphasized, and / or the stakes of the game decrease (Levitt et al. 2006, pp. 3-4). ${ }^{2}$ The Levitt et al. (2006) utility maximization model predicts that in a dictator game - a game where one subject (the dictator) has the sole decision on how to split some monetary sum between herself and another subject - keeping a greater share for oneself increases an individual's wealth, but doing so may cause the subject moral disutility. In a small stakes dictator game, the Levitt et al. (2006) model would predict transfers from the dictator to the other subject despite the wealth maximizing Nash equilibrium of the dictator not transferring any money to the other subject.

In this study, we begin by accepting the point made by Levitt et al.(2006) that moral costs or benefits matter in an individual's decision making process both inside and outside of the laboratory environment (admittedly, to different degrees). Holding the stakes of the game constant, we attempt to capture an individual's "moral" data

\footnotetext{
1 The Levitt et al. (2006) utility function is $U_{i}(a, v, n, s)=M_{i}(a, v, n, s)+W_{i}(a, v)$, where a utility-maximizing individual $i$ is faced with a choice regarding a single action $a \in(0,1), W$ is an individual's wealth, $v$ is the value of the monetary stakes of the game (as $v$ increases, the impact on $W$ increases), $M$ is the pecuniary moral cost or benefit associated with action $i, n$ is the social norm against a behavior, and $s$ is the level of scrutiny (where moral cost increase with higher levels of scrutiny).

${ }^{2}$ The study of the role of non-monetary variables in individual decision making has had a long history in economics. Perhaps the earliest treatment was Adam Smith's book The Theory of Moral Sentiments, where Smith writes that a harmony of sentiments between individuals forms the foundation for "the social regulation of personal behavior." A code of behavior that becomes critical to the "achievement of a constructive and sustainable order of free people and free markets" (cited in Evensky, 2005, p. 119). More recently, Fehr et al. (2000a, 2000b, 2002) have found altruism in public goods experiments.
} 
by having each of our research subjects complete an emotional intelligence assessment. An emotional intelligence assessment records the extent to which subjects are aware of their own emotions, how they are able to manage their own emotions, how sensitive they are to the emotions of others, their ability to respond to and negotiate with other people emotionally, and whether they are able to use their own emotions to motivate themselves. The matters addressed in the emotional intelligence assessment are similar to some of those that Levitt et al. (2006) suggest might matter in an economic decision-making environment. Moreover, we have reviewed the literature, and we believe that this paper is the first to integrate an emotional intelligence assessment and a behavioral experiment.

After each subject in our experiment completed an emotional intelligence assessment, he or she participated in a simple dictator game in which subjects decided how much, if any, of an endowment to give to another subject in a one-shot environment. Our purpose is to observe whether emotional intelligence or its component attributes (which we suggest are proxies for moral attributes) play a role in the dictator's behavior in a simple dictator experiment.

The rest of the paper is organized as follows. The first section sketches out the history of emotional intelligence research and describes the emotional intelligence assessment. Section two details the dictator experiment used in this study. Section three reports the experimental results and the results of the emotional intelligence assessment. The last section concludes the paper.

\section{EMOTIONAL INTELLIGENCE AND THE EQI}

\section{Emotional Intelligence}

Thorndike et al. (1927), Wechsler (1944), Leeper (1948), and Ellis (1956) first explored the concepts of "social intelligence," "emotional factors," and "emotional thoughts." More recently, Gardner (1983) with his highly influential work on "multiple intelligences" and Goleman et al. (1983) (who formally coined the term "emotional intelligence") explored the concept of emotional intelligence, EQ, as important and as distinct from cognitive intelligence, IQ. Cognitive intelligence refers to an individual's ability to think logically, to reason, "to concentrate and plan, to organize material, to use words and to understand, assimilate and interpret facts" (Stein et al., 2003). Emotional intelligence, on the other hand, is a "type of social intelligence which involves the ability to monitor one's own and others' emotions, to discriminate among these emotions, and to use the information to guide one's thinking and action" (Salovey et al., 1990). Emotional Intelligence incorporates five principal features: (1) being aware of one's own emotions; (2) being able to manage one's own emotions; (3) being sensitive to the emotions of others; (4) being able to respond to and negotiate with other people emotionally; and (5) being able to use one's own emotions to motivate oneself (Salovey et al., 1990).

\section{The EQ-i}

The EQ-i, the Emotional Intelligence Quotient Inventory, was developed by Reuven Bar-On in 1985 (BarOn, 2006). Bar-On defined emotional intelligence as "an array of non-cognitive capabilities, competencies, and skills that influence one's ability to succeed in coping with environmental demands and pressures" (Stein et al., 2003). The EQ-i is one of the leading tools used to measure emotional intelligence today and is used within many capacities, including leadership development, team building, recruitment of high performers, performance management, career planning, and others. The instrument was designed to measure not only overall emotional intelligence (Total EQ-i) but also a series of distinct yet related and overlapping attitudes and skills that comprise emotional intelligence and which fall into the five broad areas: Intrapersonal, Interpersonal, Adaptability, Stress Management, and General Mood (Table 1).

The Intrapersonal Dimension refers to one's ability to know and manage oneself. The Interpersonal Dimension, on the other hand, examines the capability to interact with others and establish and maintain relationships with them. Bar-On's (2006) third dimension, Adaptability, deals with an individual's ability to be realistic and flexible and solve problems effectively. Stress Management, the fourth dimension, measures the capacity to handle stress and control one's impulses. And the fifth and final scale, General Mood, evaluates the 
individual's ability to motivate him or herself, be happy, and maintain a positive out look on life. These five core areas can be further subdivided into fifteen components, as shown in Table 1.

The instrument consists of 125 items. Respondents are asked to rate each item on a five-point Likert scale ranging from "Not True of Me" (1) to "True of Me" (5). Responses to the items corresponding to each of the dimensions described above are assigned 'points' from one to five to the responses based on the participants' answer on the five-point Likert scale (e.g. if the respondent answered "Very true of me" for a positively phrased item, he or she would receive a 5; if he or she responded "Often true of me" to this same item, the person would receive a 4; and for negatively phrased items, the points are reversed, 1 point for "Very true of me") to arrive at the raw score for each of the fifteen subscales and five core areas. The raw score for the Total EQ-i is calculated by summing the scores for all of the subscale items. A mathematical transformation is then conducted of the raw scores, taking the respondent's age and gender and the normative sample data into account, to arrive at the standard scores to ensure that all of the standard scores have a mean of 100 and a standard deviation of 15 (EQ-i technical manual).

Table 1

The EQ-i Scales and the Factors They Assess ${ }^{3}$

\begin{tabular}{|c|c|}
\hline EQ-i SCALES & The EI Competencies and Skills Assessed by Each Scale \\
\hline 1. Intrapersonal & Self-awareness and self-expression: \\
\hline i. Self-Regard & $\begin{array}{l}\text { To accurately perceive, understand and accept oneself. } \\
\text { Subscales of Self-Regard: } \\
\text { 1. Internal Confidence: To feel secure, a sense of inner strength, self assured, self } \\
\text { confident, and self adequate. } \\
\text { 2. External Body: To accept positive and negative aspects of one's physical body. }\end{array}$ \\
\hline ii. Emotional Self-Awareness & $\begin{array}{l}\text { To be aware of and understand one's emotions. } \\
\text { Subscales of Emotional Self-Awareness: } \\
\text { 1. Know My Own: To know what one is feeling and why. } \\
\text { 2. Express To Others: To be able to express what one is feeling to others. }\end{array}$ \\
\hline iii. Assertiveness & To effectively and constructively express one's emotions and oneself. \\
\hline iv. Independence & To be self-reliant and free of emotional dependency on others. \\
\hline v. Self-Actualization & To strive to achieve personal goals and actualize one's potential. \\
\hline 2. Interpersonal & Social awareness and interpersonal relationship: \\
\hline i. Empathy & To be aware of and understand how others feel. \\
\hline ii. Social Responsibility & To identify with one's social group and cooperate with others. \\
\hline iii. Interpersonal Relationship & To establish mutually satisfying relationships and relate well with others. \\
\hline 3. Stress Management & Emotional management and regulation: \\
\hline i. Stress Tolerance & To effectively and constructively manage emotions. \\
\hline ii. Impulse Control & $\begin{array}{l}\text { To effectively and constructively control emotions. } \\
\text { Subscales of Impulse Control: } \\
\text { 1. Anger: To be able to control aggression and hostility. } \\
\text { 2. Impulsiveness: To be able to control impulses and irresponsible behavior. }\end{array}$ \\
\hline 4. Adaptability & Change management: \\
\hline i. Reality-Testing & To objectively validate one's feelings and thinking with external reality. \\
\hline ii. Flexibility & To adapt and adjust one's feelings and thinking to new situations. \\
\hline iii. Problem-Solving & To effectively solve problems of a personal and interpersonal nature. \\
\hline 5. General Mood & Self-motivation: \\
\hline i. Optimism & To be positive and look at the brighter side of life. \\
\hline ii. Happiness & To feel content with oneself, others and life in general. \\
\hline
\end{tabular}

\footnotetext{
${ }^{3}$ Source: Bar-On (2006)
} 


\section{THE EXPERIMENT}

Students at the University of Tampa participated in an online dictator experiment. Before the online experiment, each subject read and signed an informed consent document and their digital photo was downloaded from the university network. In a subsequent e-mail, subjects were told the start date of the experiment and were provided with a unique user identification code, which they needed to access the online experiment. Subjects began by completing an emotional intelligence assessment. After completing the assessment, subjects exited the website. Each subject was then contacted by e-mail to logon to the experimental website and begin the second phase of the experiment: the dictator game. When a subject entered the website he or she observed the following:

Welcome to the experiment!

This experiment has been designed to study economic decision-making. The instructions are simple. If you follow them carefully and make good decisions, you may earn a considerable amount of money. The money will be paid to you after the experiment has concluded. You will receive an email with information about where and when to pick up your earnings.

You have been randomly matched with another person in the experiment. You are to make all decisions individually. You have earned $\$ 10$ by completing the online assessment. The other person does not have a decision to make - what happens depends on you alone.

On the next screen, we will ask you to make a proposal about how to divide the $\$ 10$ between you and the other student. You can either leave the payment unchanged, or decrease your own thereby increasing the other person's payment.

\section{Anonymity}

Your identity will not be revealed to the other student. The person who will pay you will not know about your decision. They have simply been instructed to pay you the amount written on a standard form. The other student will not know who has done what or how the payments were generated. You will be asked to sign a receipt for the amount, but this is only for accounting purposes.

In treatment one, subjects observed the following allocation decision instructions:

\section{Allocation Decision}

You have earned $\$ 10$ by completing the online assessment. Your task is to divide the $\$ 10$ between you and the other person. The two amounts must add up to $\$ 10$. You must choose amounts that are in $\$ 1$ increments (i.e., $\$ 0, \$ 1, \$ 2, \$ 3, \ldots, \$ 9, \$ 10$ ). You will be paid that amount, and the other person will be paid the amount you decided.

\begin{tabular}{|l|c|}
\hline \multicolumn{1}{|c|}{ YOUR DECISION } & THE OTHER PERSON \\
\hline Number of dollars for you & $\square$ \\
\hline Number of dollars for the other person & $\square$ \\
\hline Submit $\quad$ Reset $\quad$ You must enter a number between 0 and 10 & \\
\hline
\end{tabular}

In treatment two, subjects observed a similar introduction, except that they were told "The other person's digital photo will be on the decision page" and "The other person will not see your digital photo." In treatment 2 , after the allocation decision instructions, subjects observed the following decision box. 


\begin{tabular}{|c|c|c|}
\hline YOUR DECISION & & THE OTHER PERSON \\
\hline Number of dollars for you & $\square$ & \\
\hline Number of dollars for the other person & $\square$ & \\
\hline
\end{tabular}

In both treatments subjects were told that they earned a $\$ 10$ endowment by completing the emotional intelligence assessment. ${ }^{4}$ In treatment two, the dictator was shown the picture of another subject; in treatment one, the dictator is not shown the picture of another subject. In both treatments, after the subject makes an allocation decision, he or she clicked the submit button. At this point, the experiment is over and he or she exited the webpage. Upon completion of the experiment, an e-mail was sent the subjects to pick up their earnings from a designated location.

\section{DATA AND RESULTS}

\section{Subject Characteristics}

Subjects were recruited between March and April of 2006 from all disciplines at the University of Tampa by a global e-mail to all students. A total of 89 subjects participated in the experiment (Table 2). There were 60 female subjects and 29 male subjects. The average age of our subjects was 20 years. Subjects were distributed across majors and academic levels (Table 2). Each of the 89 subjects played the role of dictator once in a one shot game. Many subjects were also used as the other subject; in which case they received a surprise payment at the end of the study.

Table 2

Subject Characteristics

\begin{tabular}{|l|c|c|c|}
\hline & $\begin{array}{c}\text { All Subjects } \\
(\mathrm{N}=89)\end{array}$ & $\begin{array}{c}\text { Treatment 1 } \\
(\mathrm{N}=42)\end{array}$ & $\begin{array}{c}\text { Treatment 2 } \\
(\mathrm{N}=47)\end{array}$ \\
\hline Female & 60 & 29 & 31 \\
\hline Age & 20 & 20 & 20 \\
\hline Level: & & & 12 \\
\hline Freshman & 21 & 9 & 16 \\
\hline Sophomore & 28 & 8 & 9 \\
\hline Junior & 17 & 12 & 8 \\
\hline Senior & 20 & 1 & 1 \\
\hline Graduate & 2 & 0 & 1 \\
\hline Non-Degree & 1 & & 20 \\
\hline Major: & & 16 & 5 \\
\hline Business & 36 & 7 & 1 \\
\hline Finance/Accounting & 12 & 2 & 10 \\
\hline Economics & 3 & 10 & 10 \\
\hline Liberal Arts (x-eco) & 20 & 7 & \\
\hline Science & 17 & 0 & \\
\hline Other & 1 & & \\
\hline
\end{tabular}

\footnotetext{
${ }^{4}$ Diekmann (2004) studies whether the stakes of the game are important and finds that the typical outcome generated in a dictator experiment game (a result reproduced in this study) does not erode if the stakes of the game are raised. Forsythe et al. (1994) report that doubling the endowment from $\$ 5$ to $\$ 10$ in 1988 (equal to $\$ 8.80$ and $\$ 17.60$ in 2007 dollars), in a dictator game did not affect their experimental results.
} 


\section{Treatments And Gender}

The mean (median) allocation of the dictator to the other subject is $\$ 2.88$ (\$4.00) in treatment one and $\$ 2.32$ (\$2.00) in treatment two (Table 3). Although not statistically significant, on average, dictators who are able to observe the other subject allocated fewer dollars to the other subject. The frequency of an allocation by the dictator, to the other subject, is reported in Figure 1; overall the mode is $\$ 5.00$ and the second mode is $\$ 0$.

Table 4 contains a series of regressions, each with the amount the dictator allocated to the other subject as the dependent variable. Although not statistically significant, in each of the seven regressions, treatment two dictators allocate fewer dollars to the other subject relative to treatment one.

Table 3

Mean Allocation of the Dictator by Gender and Treatment

\begin{tabular}{|l|c|c|c|c|c|}
\hline \multicolumn{1}{|c|}{ Treatment } & Gender & Mean & N & Std. Deviation & Median \\
\hline Treatment 1 & Male & 1.69 & 13 & 2.213 & 0.00 \\
\hline & Female & 3.41 & 29 & 1.991 & 5.00 \\
\hline & Total & 2.88 & 42 & 2.189 & 4.00 \\
\hline Treatment 2 & Male & 2.50 & 16 & 2.160 & 3.00 \\
\hline & Female & 2.26 & 31 & 2.190 & 2.00 \\
\hline & Total & 2.34 & 47 & 2.160 & 2.00 \\
\hline Total & Male & 2.14 & 29 & 2.183 & 2.00 \\
\hline & Female & 2.82 & 60 & 2.159 & 3.00 \\
\hline & Total & 2.60 & 89 & 2.178 & 3.00 \\
\hline
\end{tabular}

Figure 1

Frequency of the Allocations to the Other Subject

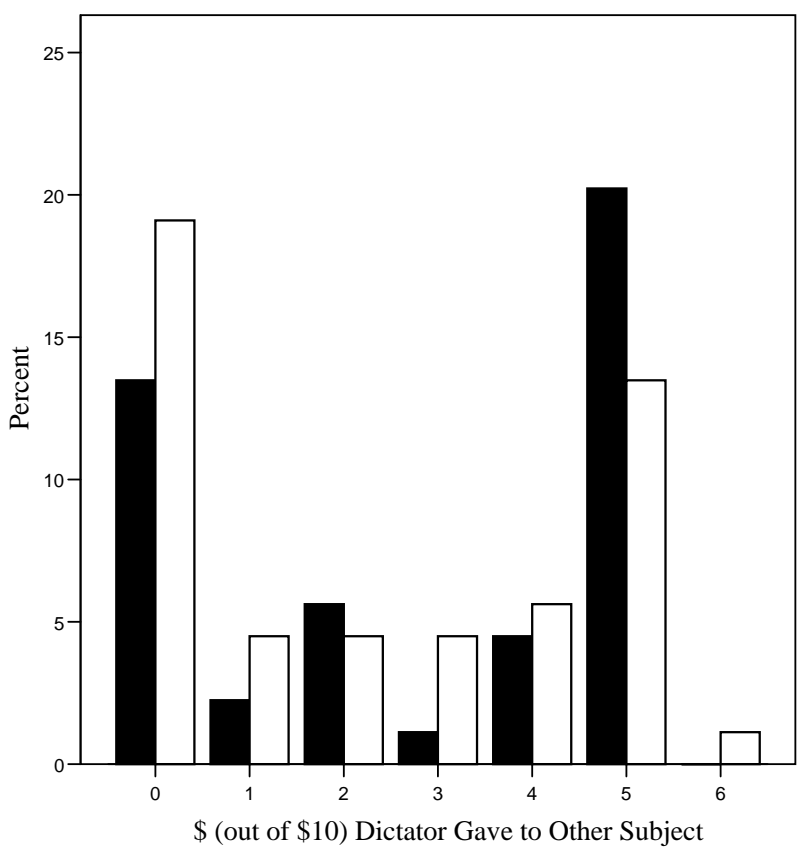

Treatment

Treatment 1

Treatment 2

\$ (out of \$10) Dictator Gave to Other Subject 
In treatment one, the mean (median) allocation to the other subject by male dictators is $\$ 1.69(\$ 0)$, while females had a mean allocation of $\$ 3.41$ (\$5.00) (Table 3). In treatment two, the mean allocation to the other subject by male dictators is $\$ 2.50$ ( $\$ 3.00)$, while females had a mean allocation of $\$ 2.26$ ( $\$ 2.00)$ (Table 3). Although not statistically significant, in each of the seven regressions in table 4, female dictators allocate more dollars to other subjects relative to male dictators. The median allocation of males increased when the other subject's photo is observed (treatment two) and the median allocation of females decreased when the other subject's photo is observed.

\section{EMOTIONAL INTELLIGENCE DATA}

The EQ-i assessment used in this research is a self-report measure of emotionally and socially intelligent behavior that provides an estimate of emotional-social intelligence of our subjects and it is the most widely used measure of emotional-social intelligence to date (Bar-On, 2004). The reliability of the EQ-i has been examined by a number of researchers over the past 20 years and a consensus of findings reveals that the Bar-On conceptual and assessment model is consistent, stable and reliable (Bar-On, 2004). Our experimental observation that dictators in this experiment have a mode offer of 50-percent to the other subject, with a secondary mode at $\$ 0$ (Figure 1), is similar to the typical result for university students. ${ }^{5}$ Taken together then, this section reports the correlations between the decisions in the simple dictator game experiment and the EQ-i assessment data of our subjects.

Model 1 in Table 4 reports the relationship between the independent variables treatment, gender, and the dictator's total emotional intelligence score (or Total EQ-i) and the dependent variable the amount that the dictator allocated to the other subject. None of the independent variables are statistically significant in this model. Therefore, we conclude that a dictator's emotional intelligence score is not a determining variable in the economic decision of how much a she or he allocates to the other subject.

Next, in an effort to capture some of the moral attributes of individual decision making behavior, we separately analyzed the five core areas of the emotional intelligence quotient inventory: intrapersonal, interpersonal, stress management, adaptability, and general mood. ${ }^{6}$ For each of the core areas, we analyzed the relationship among the independent variables treatment, gender, and the relevant EQ-i factors and the dependent variable the amount that the dictator allocated to the other subject. The results of this process are reported in model 2 through model 6 in TABLE 4.

When analyzing the five core areas, the only core area to generate statistically significant results is model 2 , which contains the factors for the core area named "intrapersonal," which measures an individual's self-awareness and self-expression. The five factors for the dictator's core area named intrapersonal are 1) self-regard, 2) emotional self-awareness, 3) assertiveness, 4) independence, and 5) self actualization. Further, in the place of self-regard, we analyzed the sub-scales "internal confidence" and "external body" and in the place of emotional self awareness, we analyzed the subscales "know my own" and "express to others."

\footnotetext{
${ }^{5}$ Henrich et al. (2001) find that among university students the typical distribution of "offers" in the dictator game typically has a mode at zero and a secondary mode at 50 -percent.

${ }^{6}$ The definitions for the EQ-i scales and sub-scales are in Table 1. The scales and sub-scales should be interpreted as defined and we do not claim that the variables take on any other definition.
} 
Table 4

Allocation by Dictator (out of \$10) to Other Subject

\begin{tabular}{|c|c|c|c|c|c|c|c|}
\hline & Model 1 & Model 2 & Model 3 & Model 4 & Model 5 & Model 6 & Model 7 \\
\hline & $\begin{array}{c}\beta \\
\text { (s.e) }\end{array}$ & $\begin{array}{c}\beta \\
\text { (s.e) }\end{array}$ & $\begin{array}{c}\beta \\
\text { (s.e) }\end{array}$ & $\begin{array}{c}\beta \\
\text { (s.e) }\end{array}$ & $\begin{array}{c}\beta \\
\text { (s.e) }\end{array}$ & $\begin{array}{c}\beta \\
\text { (s.e) }\end{array}$ & $\begin{array}{c}\beta \\
\text { (s.e) }\end{array}$ \\
\hline Constant & $\begin{array}{l}1.520 \\
(1.91)\end{array}$ & $\begin{array}{l}-.866 \\
(3.62)\end{array}$ & $\begin{array}{l}3.367 \\
(2.14)\end{array}$ & $\begin{array}{c}1.445 \\
(2.302)\end{array}$ & $\begin{array}{l}2.629 \\
(2.53)\end{array}$ & $\begin{array}{c}.260 \\
(2.11)\end{array}$ & $\begin{array}{c}15.924 * * \\
* \\
(6.332)\end{array}$ \\
\hline Treatment 2 & $\begin{array}{l}-.522 \\
(.460)\end{array}$ & $\begin{array}{l}-.126 \\
(.481)\end{array}$ & $\begin{array}{l}-.388 \\
(.471)\end{array}$ & $\begin{array}{l}-.559 \\
(.479)\end{array}$ & $\begin{array}{l}-.535 \\
(.476)\end{array}$ & $\begin{array}{l}-.454 \\
(.462)\end{array}$ & $\begin{array}{l}-.170 \\
(.454)\end{array}$ \\
\hline Female & $\begin{array}{c}.660 \\
(0.490)\end{array}$ & $\begin{array}{l}.534 \\
(.520)\end{array}$ & $\begin{array}{l}.743 \\
(.527)\end{array}$ & $\begin{array}{l}.765 \\
(.522)\end{array}$ & $\begin{array}{l}.662 \\
(.501)\end{array}$ & $\begin{array}{l}.780 \\
(.530)\end{array}$ & $\begin{array}{l}.725 \\
(.509)\end{array}$ \\
\hline Total EQ-i & $\begin{array}{l}.015 \\
(.018)\end{array}$ & & & & & & \\
\hline $\begin{array}{l}\text { Two stage Least Squares } \\
\text { adjusted total EQi }\end{array}$ & & & & & & & $\begin{array}{c}-3.069 * * * \\
(1.225)\end{array}$ \\
\hline Internal confidence & & $\begin{array}{l}-.215 \\
(.609)\end{array}$ & & & & & \\
\hline External body & & $\begin{array}{l}-.095 \\
(.414)\end{array}$ & & & & & \\
\hline Know my own & & $\begin{array}{l}-.954 * * \\
(.505)\end{array}$ & & & & & $\begin{array}{l}.861 * \\
(.460)\end{array}$ \\
\hline Express to others & & $\begin{array}{l}-.037 \\
(.492)\end{array}$ & & & & & \\
\hline Assertiveness & & $\begin{array}{l}.010 \\
(.027)\end{array}$ & & & & & \\
\hline Independence & & $\begin{array}{l}-.039 * \\
(.024)\end{array}$ & & & & & $\begin{array}{c}-.053 * * \\
(.023)\end{array}$ \\
\hline Self actualization & & $\begin{array}{l}.040 * * \\
(.022)\end{array}$ & & & & & \\
\hline Empathy & & & $\begin{array}{l}-.041 \\
(.028)\end{array}$ & & & & $\begin{array}{l}-.037 * \\
(.020)\end{array}$ \\
\hline Social responsibility & & & $\begin{array}{l}.023 \\
(.025) \\
\end{array}$ & & & & \\
\hline Interpersonal relationship & & & $\begin{array}{c}.011 \\
(.021)\end{array}$ & & & & \\
\hline Stress tolerance & & & & $\begin{array}{l}.013 \\
(.019)\end{array}$ & & & \\
\hline Anger & & & & $\begin{array}{l}.098 \\
(.329) \\
\end{array}$ & & & \\
\hline Impulsiveness & & & & $\begin{array}{l}.011 \\
(.421) \\
\end{array}$ & & & \\
\hline Reality testing & & & & & $\begin{array}{c}.001 \\
(.020)\end{array}$ & & \\
\hline Flexibility & & & & & $\begin{array}{c}.006 \\
(.021)\end{array}$ & & \\
\hline Problem solving & & & & & $\begin{array}{l}-.003 \\
(.023) \\
\end{array}$ & & \\
\hline Optimism & & & & & & $\begin{array}{l}.023 \\
(.024)\end{array}$ & \\
\hline Happiness & & & & & & $\begin{array}{l}.003 \\
(.024)\end{array}$ & \\
\hline R-squared & 0.044 & 0.144 & 0.060 & 0.043 & 0.037 & 0.060 & 0.396 \\
\hline Durbin-Watson & 2.011 & 1.959 & 1.914 & 2.027 & 1.987 & 2.039 & 1.913 \\
\hline
\end{tabular}

* (**) [***] Statistically significant at the $10 \%(5 \%)[1 \%]$ level. 
We observe the following about the dictator's behavior. First, the more independence the dictator has, the fewer dollars she or he allocates to the other subject. Independence in the emotional intelligence assessment is defined to be self-reliant and free of emotional dependency on others (Salovey et al., 1990). Second, the more the dictator claims that she or he knows what she or he is feeling and why (know-my-own), the less he or she allocate to the other subject. Thus, on the margin, the more self-reliant and free of emotional dependency and the more the dictator claims to know what he or she are feeling and why, the closer the subject's behavior approaches the predicted Nash equilibrium in the one-shot dictator game (the Nash equilibrium tells us that the dictator allocates $\$ 0$ to the other subject). Whether or not the subjects are actually more self-interested outside of this experiment is an open question; however, we may claim that the subjects with the above characteristics (as defined by the EQ-i assessment) act in a way that is more consistent with the equilibrium behavior of homo economicus. Third, the more the dictator claims that they strive to achieve personal goals and actualize their potential - the factor named selfactualization, the more she or he allocates to the other subject. We classify self-actualization, therefore, as a moral variable - as it increases, using the language of Levitt et al. (2006), an individual's pecuniary moral benefit associated with a given action increases.

Finally, we analyzed the relationship among the independent variables treatment, gender, and the factors independence, know my own, empathy and an adjusted emotional intelligence variable ${ }^{7}$ and the dependent variable the amount the dictator allocated to the other subject. We selected the independent variables independence, know my own, and empathy, and not others, because of their importance in discovering the moral motives of the dictator, and not because of their significance in the other regressions. Table 5 reports the items from the EQ-i assessment on the three individual dimensions used in this model. The econometric results are reported in Table 4, model 7.

By analyzing the dictator's behavior in this way, we observe the following four results. First, the more the dictator claims that she or he knows what she or he is feeling and why, the more they allocate to the other subject (pvalue $=0.065){ }^{8}$ Second, the more independent (self-reliant and free of emotional dependency) the dictator is, the less she or he allocates to the other subject. Third, the more empathy the subject has (empathy is defined by the EQ$\mathrm{i}$ to mean how much the subject claims that he or she is aware of and understands how others feel), the less they allocate to the other subject. This outcome is interesting because it offers a result that is counter to conventional wisdom - the more empathic an individual, the fewer dollars they allocate to another subject in a simple dictator game. If one accepts the definition of empathy ${ }^{9}$ used here, then as this moral attribute marginally increases, observed subject behavior increasingly correlates with the typical self-interested wealth maximizing individual. And fourth, the higher the adjusted emotional intelligence number (adjusted for independence, know my own, and empathy), the less she or he allocates to the other subject. This last result must be interpreted with caution because it is not a measure of emotional intelligence and its significance as a measure of emotional intelligence has not been scientifically validated (whereas the EQ-i has been validated, see Bar-On (2004)). The variable adjusted EQ-i's sole purpose in model 7 is technical - it allows us to isolate the effects of independence, know my own, and empathy on the dictator's decision.

\footnotetext{
${ }^{7}$ We used two stage least squares to adjust for the endogenous variables independence, know my own, and empathy. Thus, roughly speaking, the adjusted EQ-i score is equal to the total EQ-i score minus the scores for independence, know my own, and empathy.

${ }^{8}$ The sign on this variable changed relative to model 2. However, in model 7 we control for all other EQ-i measures in the adjusted EQ-i variable; this was not done in model 2.

9 The definition of empathy is from the EQ-i assessment and it is based on the eight questions in Table 5. Specifically, the definition of empathy used here deals with how the dictator claims to understand how others feel, which is in contrast to the definition of "know my own" which deals with how the dictator claims to understand how she or he is feeling.
} 
Table 5

Items for Specific Dimensions $^{10}$

\begin{tabular}{|ll|}
\hline \multicolumn{2}{|c|}{ Independence } \\
1. & I prefer a job in which I'm told pretty much what to do. \\
2. & When working with others, I tent to rely more on their ideas than my own. \\
3. & I prefer others to make decisions for me. \\
4. & It's hard for me to make decisions on my own. \\
5. & I'm more of a follower than a leader. \\
6. & I tend to cling to others. \\
7. & I seem to need other people more than they need me. \\
\hline Empathy & \\
1. & I'm unable to understand the way other people feel. \\
2. & I'm good at understanding the way other people feel. \\
3. & My friends can tell me intimate things about themselves. \\
4. & I would stop and help a crying child to find his or her parents, even if I had to be somewhere else at that time. \\
5. & I care what happens to other people. \\
6. & I'm sensitive to the feelings of others. \\
7. & It's hard for me to see people suffer. \\
8. & I avoid hurting other people's feelings. \\
\hline Know My Own - Emotional Self Awareness subscale \\
1. & I'm in touch with my emotions. \\
2. & It's hard for me to understand the way I feel. \\
3 & I'm aware of the way I feel. \\
4. & Even when I'm upset, I'm aware of what's happening to me. \\
\hline
\end{tabular}

\section{SUMMARY AND CONCLUSION}

A goal of this paper is to determine if moral factors captured in an emotional intelligence assessment play a role in economic decisions made by student subjects in a simple dictator game. We do not find a statistically significant relationship between the total EQ-i score and the amount that the dictators contributed to other subjects. Neither the dictator's gender nor the treatment (providing a picture of the other subject) was found to alter contributions to the other subject at a statistically significant level. We did find a statistically significant relationship between the amount of the dictator's contribution and the EQ-i Intrapersonal Dimensions: independence (to be selfreliant and free of emotional dependency on others), know-my-own (to know what one is feeling and why), and self actualization (to strive to achieve personal goals and actualize one's potential). When we test the intrapersonal elements of the EQ-i measure (along with treatment and gender) against contribution behavior we observed that those subjects who were more independent and were more aware of their own emotions were more likely to allocate smaller contributions to the other subject. On the other hand, those who were more self-actualized (strive to achieve personal goals) were more likely to contribute more to the other subject in the game. In Model 7, we also found a significant relationship between dictator contributions and an adjusted EQ-i score, independence, self awareness and empathy.

In combination, our results are relevant to economists and experimental researchers in other disciplines who are interested in 1) the preference sets economic decision-makers and 2) experimental design protocols. First, it appears that the aforementioned EQ-i factors and sub-factors may provide useful information about subject preferences. Thus, an important message of this paper is that we must account for the moral attributes revealed in an emotional intelligence assessment in an effort to fully understand human decision-making; the self-interested actions of homo economicus are a large part of what is going on, but specific moral attributes also matter. We believe that our approach is preferred to using "altruism" as a catch-all term for a lot of non-equilibrium behavior. Second, as Levitt et al. (2006) suggest, because the moral attributes of economic actors are so very important, we must attempt to control for them in laboratory experiment protocols and in field experiment protocols. Therefore, we recommend to researchers conducting decision-making experiments (and field experiments when it is feasible) that they consider

\footnotetext{
${ }^{10}$ All respondents are asked to rate each item on a five-point Likert scale ranging from "Not True of Me" (1) to "True of Me" (5).
} 
having their subjects complete an EQ-i assessment prior to participating in decision-making experiments. The marginal cost of this activity is low because the assessment takes less than 30 minutes to complete, and it may be purchased for a modest emolument. On the other hand, if one finds the entire assessment too costly, we suggest using the subset of EQ-i questions pertaining to know-my-own, independence, and empathy (listed in Table 5) in a pre-experiment survey.

\section{ACKNOWLEDGEMENTS}

Research funding provided by the University of Tampa's Faculty Development Dana Grant and the David Delo Research Professor Grant.

\section{REFERENCES}

1. Bar-On, R. (2004). The Bar-On Emotional Quotient Inventory (EQ-i): Rationale, Description, and Summary of Psychometric Properties. In Geher, G. (Ed.), Measuring emotional intelligence: Common ground and controversy. Hauppauge, NY: Nova Science Publishers, 111-142.

2. Bar-On, R. (2006). The Bar-On model of emotional-social intelligence (ESI). Psicothema, 18, supplement, 13-25.

3. Diekmann, A. (2004). The Power of Reciprocity: Fairness, Reciprocity, and Stakes in Variants of the Dictator Game. Journal of Conflict Resolution, 48(4), August, 487-505.

4. Ellis, A. (1956). An operational reformulation of some of the basic principles of psychoanalysis. In Feigel, H., \& Scriven, M. (Eds.), The foundations of science and the concepts of psychology and psychoanalysis. Minneapolis: University of Minnesota Press.

5. Evensky, J. (2005). Adam Smith's Theory of Moral Sentiments: On Morals and Why they Matter to a Liberal Society of Free People and Free Markets. Journal of Economic Perspectives, 19(3), 109-130.

6. Fehr, E. \& Gachter, S. (2000a). Cooperation and Punishment in Public Goods Experiments. American Economic Review, 90(4), 980-994.

7. Fehr, E. \& Gachter, S. (2000b). Fairness and Retaliation: The Economics of Reciprocity. Journal of Economic Perspectives, 14(3), 159-181.

8. Fehr, E. \& Gachter, S. (2002). Altruistic Punishment in Humans. Nature, 415(January), 137-140.

9. Forsythe, R., Horowitz, J.L., Savin, N.E., \& Sefton, M. (1994). Fairness in Simple Bargaining Experiments. Games and Economic Behavior, 6(3), 347-369.

10. Gardner, H. (1983). Frames of Mind. New York: Basic Books.

11. Goleman, D., \& Salovey, P. (1983). What is Emotional Intelligence. In Salovey, P. and Sluyter. D. (Eds.), Emotional Development, Emotional Literacy, and Emotional Intelligence: Implications for Educators. New York: Basic Books.

12. Henrich, J., Boyd, R., Bowles, S., Camerer, C., Fehr, E., Gintis, H., \& McElreath, R. (2001). In Search of Homo Economicus: Behavioral Experiments in 15 Small-Scale Societies. American Economic Review, 91 (2), 73-78.

13. Leeper, R. W. (1948). A motivational theory of emotions to replace emotions as disorganized responses. Psychological Review, 55, 5-21.

14. Levitt, S. \& List, J. (2006). What do Laboratory Experiments Tell Us About the Real World? Journal of Economic Perspectives, forthcoming.

15. Salovey, P. \& Meyer, J. D. (1990). Emotional Intelligence. Imagination, Cognition, and Personality, 9: 185-211.

16. Stein, S. J. \& Book, H. E. (2003). The EQ Edge: Emotional Intelligence and Your Success. New York, NY: Multi-Health Systems, Inc.

17. Thorndike, E., Bergman, E., Cobb M., \& Woodyeard, E. (1927). The Measurement of Intelligence. Arno press.

18. Weschsler, D. (1944). The measurement of adult intelligence. The Williams \& Wilkins company. 


\section{NOTES}

